\title{
Surgery in asymptomatic patients with colorectal cancer and unresectable liver metastases: the authors' experience
}

\author{
Carlo Boselli' \\ Claudio Renzi ${ }^{2}$ \\ Alessandro Gemini' \\ Elisa Castellani' \\ Stefano Trastulli ${ }^{2}$ \\ Jacopo Desiderio ${ }^{2}$ \\ Alessia Corsi ${ }^{2}$ \\ Francesco Barberini' \\ Roberto Cirocchi ${ }^{2}$ \\ Alberto Santoro ${ }^{3}$ \\ Amilcare Parisi ${ }^{4}$ \\ Adriano Redler ${ }^{3}$ \\ Giuseppe Noya' \\ 'Department of General and \\ Oncologic Surgery, University of \\ Perugia, Perugia, ${ }^{2}$ Department of \\ General Surgery, University of \\ Perugia, St Maria Hospital, Terni, \\ ${ }^{3}$ Department of Surgical Sciences, \\ Sapienza University of Rome, Rome, \\ ${ }^{4}$ Department of Digestive Surgery, \\ St Maria Hospital, Terni, Italy
}

This article was published in the following Dove Press journal:

OncoTargets and Therapy

26 March 2013

Number of times this article has been viewed
Purpose: In asymptomatic patients with Stage IV colorectal cancer, the debate continues over the efficacy of primary resection compared to chemotherapy alone. The aim of this study was to define the optimal management for asymptomatic patients with colorectal cancer and unresectable liver metastases.

Patients and methods: Patients receiving elective surgery $(n=17)$ were compared to patients receiving chemotherapy only $(n=31)$. Data concerning patients' demographics, location of primary tumor, comorbidities, performance status, Child-Pugh score, extension of liver metastases, size of primary, and other secondary locations were collected.

Results: Thirty-day mortality after chemotherapy was lower than that after surgical resection ( $19.3 \%$ versus $29.4 \%$; not significant). In patients with $>75 \%$ hepatic involvement, mortality at 1 month was higher after receiving surgical treatment than after chemotherapy alone $(50 \%$ versus $25 \%$ ). In patients with $<75 \%$ hepatic involvement, 30 -day mortality was similar in both groups (not significant). Thirty-day mortality in patients with Stage T3 was lower in those receiving chemotherapy ( $16.7 \%$ versus $30 \%$; not significant). Overall survival was similar in both groups. The risk of all-cause death after elective surgery (2.1) was significantly higher than in patients receiving chemotherapy only $(P=0.035)$.

Conclusion: This study demonstrated that in palliative treatment of asymptomatic unresectable Stage IV colorectal cancer, the overall risk of death was significantly higher after elective surgery compared to patients receiving chemotherapy alone. However, in the literature, there is no substantial difference between these treatments. New studies are required to better evaluate outcomes.

Keywords: large bowel, tumor, inoperable liver replacement, palliative surgery, 30-day mortality

\section{Introduction}

Colorectal cancer (CRC) represents more than $9 \%$ of all new cancer cases worldwide, ${ }^{1}$ and in 2002, more than 1 million new cases were diagnosed. In the US, the incidence of this malignancy has decreased by $3.0 \%$ in men and $2.2 \%$ in women in 1998-2006, with a reduction in male mortality of $3.9 \%$ in 2002-2006. ${ }^{2}$ However, an increased incidence of CRC has occurred in Europe, particularly in the southeastern countries. ${ }^{3}$ Among patients with newly diagnosed CRC, 20\%-30\% have liver metastases, ${ }^{4,5} 10 \%-15 \%$ have peritoneal carcinomatosis, ${ }^{6,7}$ and $10 \%-25 \%$ have lung metastases..$^{8-10}$

According to the European Society for Medical Oncology guidelines, hepatectomy for patients with metastatic $\mathrm{CRC}$ is to be performed only with curative intent following the criteria of oncological radicality and if it is indicated that there is enough remnant
Correspondence: Claudio Renzi

St Maria Hospital, Via Tristano di Joannuccio 4, Terni 05100, Italy

Tel +39 744205442

Fax +39744 205 III

Email renzicla@virgilio.it 
liver parenchyma following the resection $(>30 \%)$ and/or in the absence of unresectable multivisceral spreading of the disease or carcinomatosis. ${ }^{11,12}$

Treatment of advanced stages of CRC, especially in patients not eligible for curative surgery, consists of medical therapies. The availability of new polychemotherapeutic regimens (5-fluorouracil, folinic acid, and oxaliplatin; FOLFOX) in combination with biologic agents (monoclonal antibodies such as bevacizumab, cetuximab, and panitumumab) has markedly improved the median survival of patients in advanced stages, with no increase in the incidence of complications. ${ }^{13-16}$

In a retrospective study, $93 \%$ of patients with Stage IV CRC on chemotherapy did not develop complications related to the primary tumor. ${ }^{17}$ In patients with obstructive tumor, the use of stents allowed them to be quickly started on systemic chemotherapy. ${ }^{18,19}$ Nevertheless, in asymptomatic patients with Stage IV CRC, the debate continues over the efficacy of primary neoplasia resection compared to chemotherapy alone. $^{20}$

The aim of this study was to determine if there was any improvement in overall survival and a reduction of posttreatment mortality after resection of the primary tumor, with respect to nonoperative treatment in patients with Stage IV $\mathrm{CRC}$ and unresectable liver metastases.

\section{Patients and methods}

Data on patients with synchronous unresectable liver metastases from CRC who consecutively underwent palliative therapy between January 2010 and December 2011 were retrospectively reviewed. Among patients with rectal cancer, only those with intraperitoneal localization were selected because extraperitoneal rectal cancer with unresectable liver metastases is best treated with chemotherapy and radiation therapy as an effective palliative treatment. None of the 48 patients included in this multicentric study had bowel obstruction, bleeding, or perforation.

Seventeen patients (operative group) underwent elective palliative surgery consisting of colonic resection, 14 of whom had open surgery by median laparotomy, two with primary tumor in rectosigmoid colon underwent laparoscopic colorectal dissection followed by suprapubic laparotomy in which total mesorectal excision and colorectal anastomosis were performed, and one with right $\mathrm{CRC}$ had laparoscopic exploration followed by total laparotomic right colectomy due to local extension of the disease. Seven of the patients who underwent elective surgery had neoplastic stenosis; however, despite this, obstinate constipation was reported.
Thirty-one patients (nonoperative group) received chemotherapy alone, leaving the primary tumor in place, ie, nonoperative management (NOM). In this group, 24 patients received FOLFOX plus bevacizumab as firstline therapy. FOLFOX only was administered to the remaining seven patients who were not able to tolerate the combination. Switching to second-line therapy was not needed. Administration of bevacizumab was suspended at 3 months in six patients because of drug-related toxicity or worsening of their condition and in two patients because disease control was reached.

Age, comorbidities, and performance status, and the risk of complications (obstruction and perforation) were the criteria used to choose between the resection of the primary tumor and NOM (Table 1). Thirty-day overall mortality and overall survival were the primary and secondary endpoints assessed.

Statistics on the clinical characteristics of patients were calculated by Fisher's exact test for $2 \times 2$ comparisons and by Pearson's Chi-squared test for comparisons greater than $2 \times 2$ ( $95 \%$ confidence interval, $\alpha=0.05$ ). A multivariate analysis for 30-day mortality and overall survival was performed by Cox logistic regression.

The mean age of the patients was lower in the operative group (Table 1). Local extension of the disease was

Table I Clinical characteristics of the patients according to treatment

\begin{tabular}{|c|c|c|c|}
\hline Clinical characteristic & $\begin{array}{l}\text { Elective } \\
\text { surgery }\end{array}$ & NOM & $P$ \\
\hline Average age (range), years & $70(54-84)$ & $73(60-87)$ & \\
\hline \multicolumn{4}{|l|}{ Primary tumor localization } \\
\hline Right colon & $4(23.5 \%)$ & $7(22.6 \%)$ & 0.22 \\
\hline Left colon & 7 (4I.4\%) & $6(19.4 \%)$ & \\
\hline Rectosigmoid colon & $6(35.3 \%)$ & $18(58 \%)$ & \\
\hline \multicolumn{4}{|l|}{ Number of comorbidities } \\
\hline 0 & $4(23.5 \%)$ & $7(22.6 \%)$ & 0.60 \\
\hline I & $9(52.9 \%)$ & I I (35.5\%) & \\
\hline 2 & $3(17.6 \%)$ & $10(32.2 \%)$ & \\
\hline 3 & I (6\%) & $3(9.7 \%)$ & \\
\hline \multicolumn{4}{|l|}{ Performance status } \\
\hline ASA I/ECOG 0 & $6(35.3 \%)$ & $7(22.6 \%)$ & 0.60 \\
\hline ASA II/ECOG I & $8(47.1 \%)$ & $16(51.6 \%)$ & \\
\hline ASA III/ECOG 2 & $3(17.6 \%)$ & $8(25.8 \%)$ & \\
\hline \multicolumn{4}{|l|}{ Child before treatment } \\
\hline A & II (64.7\%) & $14(45.2 \%)$ & 0.24 \\
\hline B & $6(35.3 \%)$ & I 7 (54.8\%) & \\
\hline \multicolumn{4}{|c|}{ Hepatic parenchyma replaced by metastases } \\
\hline$<50 \%$ & $9(53 \%)$ & 13 (42\%) & 0.51 \\
\hline $50 \%-75 \%$ & $6(35 \%)$ & $10(32 \%)$ & \\
\hline$>75 \%$ & $2(12 \%)$ & 8 (26\%) & \\
\hline
\end{tabular}

Abbreviations: ASA, American Society of Anesthesiologists; ECOG, Eastern Cooperative Oncology Group; NOM, nonoperative management. 
determined by computed tomography scan and pathological examination in the operative group, and by computed tomography scan only in the NOM group (Table 1).

\section{Results}

Overall mortality within 30 days of commencing palliative chemotherapy was lower than that of surgical resection (five versus six), even though this outcome was not statistically significant. In the operative group, three patients died of liver failure presenting hepatorenal syndrome, two patients died of heart failure, and six patients had postoperative complications (three wound infections, one urinary tract infection, and two with bronchopneumonia). Of the six patients who received chemotherapy only, four died of hepatorenal syndrome and two died of heart failure.

In patients with $>75 \%$ of the parenchyma replaced by metastases, mortality after treatment was found to be $50 \%$ if on elective surgery and $25 \%$ if on chemotherapy alone. The reported difference between the two groups of patients for $<75 \%$ hepatic involvement of the volume was minimal (50\%-75\%: $2 / 6$ versus $2 / 10$ and $<50 \%$ : $2 / 9$ versus $2 / 13$ for elective surgery and NOM, respectively) (Tables 2 and 3 ).

Thirty-day mortality in patients with Stage T3 was lower in the group receiving chemotherapy, although this outcome was not statistically significant (3/10 versus $2 / 12$ for elective surgery and NOM, respectively). In patients with Stage T4, local extension of the tumor did not appear to affect 30-day mortality since the difference between the two groups was minimal (2/7 versus 4/19 for elective surgery and NOM, respectively) (Tables 2 and 3 ).

Secondary localizations in addition to hepatic replacement did not affect 30-day mortality. The two groups were not comparable because not all patients presented extrahepatic metastases (Tables 2 and 3 ).

Of the patients who underwent elective surgery, eleven started palliative chemotherapy (six received FOLFOX plus bevacizumab and five received FOLFOX only) and six died of disease or complications before starting it. The mean interval between surgery and starting postoperative chemotherapy was 5 weeks.

The mean and median follow-up was 8 months and 7 months, respectively. The mean and median overall survival of the patients receiving elective surgery was 6 months and 4 months, respectively. For the patients who underwent palliative chemotherapy only, the mean and median overall survival was 7 months and 5 months, respectively. The 1-year overall survival rate was $17.6 \%$ versus $19.4 \%$ for elective surgery and chemotherapy alone, respectively (Figure 1).

Multivariate analysis of the data demonstrated that there were no statistically significant differences in 30-day mortality. On the other hand, data analysis using the Cox regression model demonstrated that the risk of all-cause death was significantly higher after elective surgery $(2.1 ; 95 \%$ confidence interval $1.06-4.5 ; P=0.035$; adjusted to liver replacement

Table 2 Factors affecting 30-day overall mortality and overall survival after elective surgery

\begin{tabular}{|c|c|c|c|c|c|}
\hline $\begin{array}{l}\text { Patient } \\
\text { (by date) }\end{array}$ & $\begin{array}{l}\text { Overall survival from the } \\
\text { start of therapy (months) }\end{array}$ & $\begin{array}{l}\text { Hepatic } \\
\text { involvement }\end{array}$ & $\begin{array}{l}\text { Local } \\
\text { extension }(T)\end{array}$ & $\begin{array}{l}\text { Lung } \\
\text { metastases }\end{array}$ & $\begin{array}{l}\text { Peritoneal } \\
\text { metastases }\end{array}$ \\
\hline$I$ & 1 & $<50 \%$ & 4 & $x$ & $x$ \\
\hline 2 & 2 & $50 \%-75 \%$ & 4 & & $x$ \\
\hline 3 & 9 & $<50 \%$ & 3 & $x$ & \\
\hline 4 & I & $50 \%-75 \%$ & 3 & & $x$ \\
\hline 5 & 8 & $<50 \%$ & 4 & & \\
\hline 6 & 15 & $<50 \%$ & 3 & & \\
\hline 7 & 3 & $<50 \%$ & 3 & $x$ & $x$ \\
\hline 8 & 4 & $50 \%-75 \%$ & 3 & & \\
\hline 9 & 1 & $50 \%-75 \%$ & 4 & $x$ & \\
\hline 10 & $20 *$ & $<50 \%$ & 3 & & \\
\hline 11 & 1 & $>75 \%$ & 3 & & \\
\hline 12 & 10 & $<50 \%$ & 3 & & \\
\hline 13 & 3 & $>75 \%$ & 4 & & \\
\hline 14 & 12 & $<50 \%$ & 3 & & \\
\hline 15 & 4 & $50 \%-75 \%$ & 4 & $x$ & \\
\hline 16 & 1 & $<50 \%$ & 4 & & $x$ \\
\hline 17 & 6 & $50 \%-75 \%$ & 3 & & \\
\hline
\end{tabular}

Note: *Alive October 2012.

Abbreviations: $X$, positive; -, negative. 
Table 3 Factors affecting 30-day overall mortality and overall survival after nonoperative management

\begin{tabular}{|c|c|c|c|c|c|}
\hline $\begin{array}{l}\text { Patient } \\
\text { (by date) }\end{array}$ & $\begin{array}{l}\text { Overall survival from the } \\
\text { start of therapy (months) }\end{array}$ & $\begin{array}{l}\text { Hepatic } \\
\text { involvement }\end{array}$ & $\begin{array}{l}\text { Local } \\
\text { extension }(T)\end{array}$ & $\begin{array}{l}\text { Lung } \\
\text { metastases }\end{array}$ & $\begin{array}{l}\text { Peritoneal } \\
\text { metastases }\end{array}$ \\
\hline I & 11 & $<50 \%$ & 3 & & \\
\hline 2 & 1 & $50 \%-75 \%$ & 4 & $x$ & $x$ \\
\hline 3 & 22 & $<50 \%$ & 4 & & \\
\hline 4 & 7 & $>75 \%$ & 3 & $x$ & \\
\hline 5 & 4 & $>75 \%$ & 4 & & $x$ \\
\hline 6 & 11 & $<50 \%$ & 4 & & \\
\hline 7 & 3 & $>75 \%$ & 4 & $x$ & $x$ \\
\hline 8 & 12 & $<50 \%$ & 4 & & \\
\hline 9 & 4 & $50 \%-75 \%$ & 3 & & $x$ \\
\hline 10 & 1 & $>75 \%$ & 3 & $x$ & \\
\hline 11 & 8 & $<50 \%$ & 4 & & \\
\hline 12 & 6 & $<50 \%$ & 3 & $x$ & \\
\hline 13 & 2 & $>75 \%$ & 4 & & $x$ \\
\hline 14 & I & $50 \%-75 \%$ & 3 & & $x$ \\
\hline 15 & 16 & $<50 \%$ & 3 & & \\
\hline 16 & 5 & $>75 \%$ & 4 & $x$ & \\
\hline 17 & $19 *$ & $<50 \%$ & 3 & & \\
\hline 18 & 1 & $50 \%-75 \%$ & 4 & & $x$ \\
\hline 19 & 4 & $50 \%-75 \%$ & 4 & $x$ & \\
\hline 20 & 13 & $<50 \%$ & 3 & & \\
\hline 21 & 5 & $50 \%-75 \%$ & 4 & $x$ & \\
\hline 22 & I & $>75 \%$ & 4 & & \\
\hline 23 & 3 & $50 \%-75 \%$ & 3 & $x$ & \\
\hline 24 & 8 & $<50 \%$ & 4 & & \\
\hline 25 & 2 & $>75 \%$ & 4 & & $x$ \\
\hline 26 & 10 & $<50 \%$ & 4 & & \\
\hline 27 & 3 & $50 \%-75 \%$ & 4 & $x$ & $x$ \\
\hline 28 & $12 *$ & $<50 \%$ & 3 & & \\
\hline 29 & 1 & $50 \%-75 \%$ & 4 & & $x$ \\
\hline 30 & 4 & $50 \%-75 \%$ & 4 & & $x$ \\
\hline 31 & 7 & $<50 \%$ & 3 & $x$ & \\
\hline
\end{tabular}

Note: *Alive October 2012.

Abbreviations: $\mathrm{X}$, positive; -, negative.

and other metastases) compared to patients receiving chemotherapy only (Tables 2 and 3).

Overall the two groups showed similar performance status. The difference between the two groups was greatest for American Society of Anesthesiologists I/ Eastern Cooperative Oncology Group 0 (Table 1). Furthermore, patients undergoing surgery had a better hepatic function since they had a smaller metastatic liver replacement than those receiving chemotherapy alone (Table 1).

\section{Discussion}

Resection of the primary tumor is necessary for patients with complications, whereas chemoradiotherapy in combination with targeted agents appears safe and seems a suitable alternative for patients without complications. ${ }^{23}$ After resection of the primary tumor, adjuvant therapy should be promptly undertaken as a delay may decrease its efficacy. ${ }^{24}$ According to Galizia et al, this occurrence may be balanced by a better response rate to chemotherapy in selected patients before primary tumor debulking. ${ }^{25}$ The current analysis doesn't suggest that primary tumor resection is a safe and effective treatment of asymptomatic patients with Stage IV CRC when not radically resectable.

Liver tumor burden has been recognized as an independent risk factor for poor outcome, regardless of therapy. Thus, patients with extensive $(>75 \%)$ hepatic tumor involvement carry an extremely unfavorable prognosis. ${ }^{26}$ Hepatic parenchymal replacement is significantly related to survival. Hepatic tumor burden $>50 \%$ is related to poor overall survival. ${ }^{27}$ Bilobar liver involvement is related with an even greater unfavorable prognosis. ${ }^{28}$

In palliative treatment of uncomplicated patients affected by CRC with unresectable liver metastases, chemoradiotherapy combined with biological agents is 


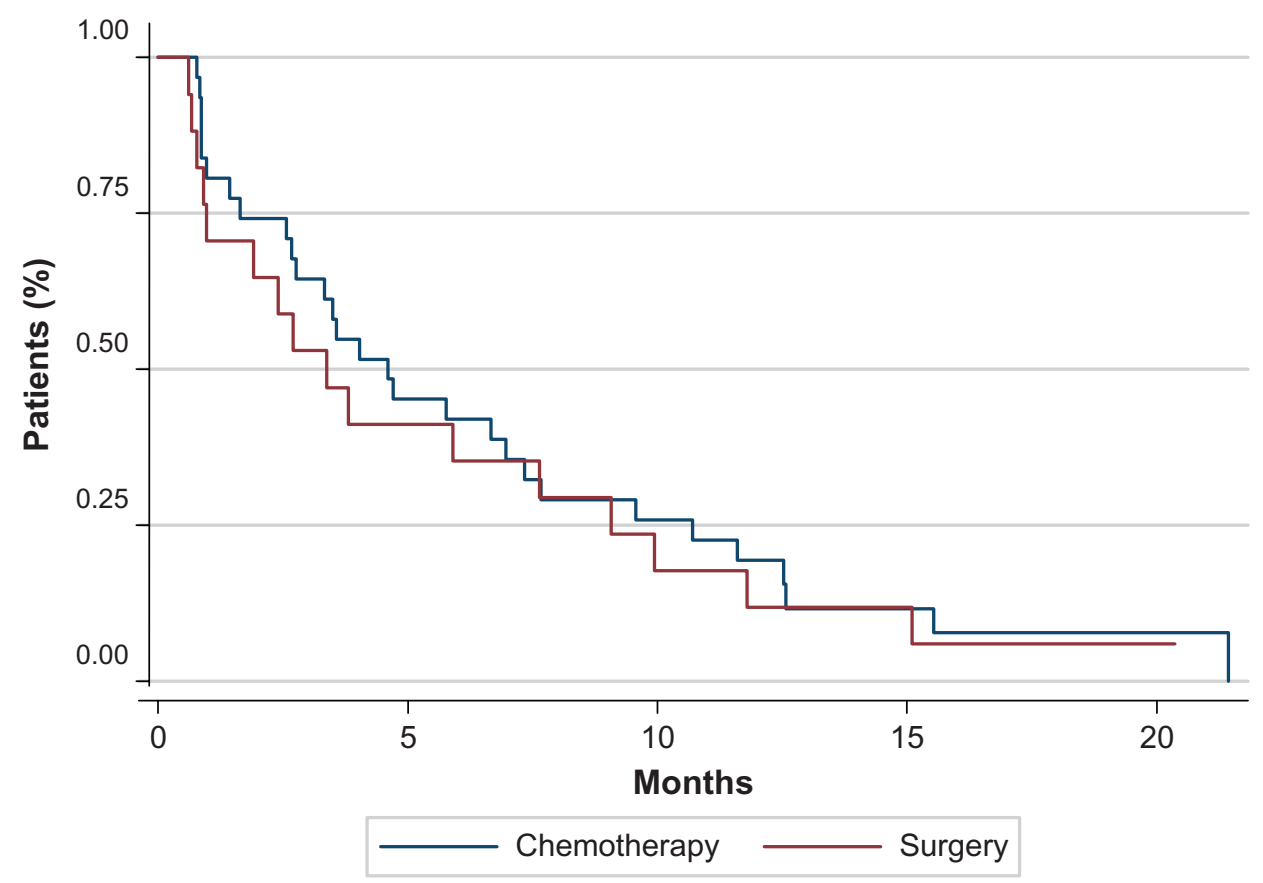

Figure I Kaplan-Meier survival curves according to treatment.

a suitable alternative to surgical resection of the primary tumor.

Asymptomatic patients with a liver metastasis involving $<50 \%$ of the parenchyma, when undergoing resection of the primary tumor, display a survival rate similar to patients on chemotherapy alone (Tables 2 and 3). In asymptomatic patients with a replaced liver volume of 50\%-75\%, surgery showed no benefits in terms of survival over NOM (posttreatment mortality $33.3 \%$ versus $20 \%$ ), as recently shown by Kleespies et al. ${ }^{27}$ This data is even more significant in patients with metastases involving $>75 \%$ of the liver volume (posttreatment mortality 50\% versus 25\%) (Tables 2 and 3 ).

Local neoplastic extension is not an independent predictor of survival. ${ }^{29}$ In the current study, it was demonstrated that in Stage T3 and T4 local extension of the primary tumor, elective surgery presents no benefit in terms of survival compared to NOM (posttreatment mortality Stage T3: 30\% versus 16.7\% and Stage T4: 28.6\% versus 21\%) (Tables 2 and 3).

Peritoneal carcinomatosis is an independent prognostic factor, ${ }^{30}$ and it is also recognized as an important risk factor for obstruction. ${ }^{31}$ In the current study, peritoneal carcinomatosis appeared not to influence posttreatment mortality.

The main bias of this study was the small number of patients analyzed in a retrospective way. With the exception of overall risk of death, which was higher after elective surgery, no significant difference in 30-day mortality and overall survival was found between the two groups of patients.

\section{Conclusion}

This study shows that in palliative treatment of asymptomatic unresectable Stage IV CRC, the risk of all-cause death was significantly higher after elective surgery compared to patients receiving chemotherapy only. However, in the literature, there is no substantial difference between these two treatments. ${ }^{32}$ Therefore, it is crucial to undertake new studies to evaluate and compare the results in terms of quality of life in both groups of patients.

\section{Disclosure}

The authors report no conflicts of interest in this work.

\section{References}

1. Parkin DM, Bray F, Ferlay J, Pisani P. Global cancer statistics, 2002. CA Cancer J Clin. 2005;55(2):74-108.

2. Edwards BK, Ward E, Kohler BA, et al. Annual report to the nation on the status of cancer, 1975-2006, featuring colorectal cancer trends and impact of interventions (risk factors, screening, and treatment) to reduce future rates. Cancer. 2010;116(3):544-573.

3. Ferlay J, Autier P, Boniol M, Heanue M, Colombet M, Boyle P. Estimates of the cancer incidence and mortality in Europe in 2006. Ann Oncol. 2007;18(3):581-592.

4. Manfredi S, Lepage C, Hatem C, Coatmeur O, Faivre J, Bouvier AM Epidemiology and management of liver metastases from colorectal cancer. Ann Surg. 2006;244(2):254-259. 
5. Simmonds PC, Primrose JN, Colquitt JL, Garden OJ, Poston GJ, Rees M. Surgical resection of hepatic metastases from colorectal cancer: a systematic review of published studies. Br J Cancer. 2006;94(7): 982-999.

6. Dawson LE, Russell AH, Tong D, Wisbeck WM. Adenocarcinoma of the sigmoid colon: sites of initial dissemination and clinical patterns of recurrence following surgery alone. J Surg Oncol. 1983;22(2):95-99.

7. Chu DZ, Lang NP, Thomson C, Osteen PC, Westbrook KC. Peritoneal carcinomatosis in nongynecologic malignancy: a prospective study of prognostic factors. Cancer. 1989;63(2):364-367.

8. Inoue $\mathrm{M}$, Ohta $\mathrm{M}$, Iuchi $\mathrm{K}$, et al. Benefits of surgery for patients with pulmonary metastases from colorectal carcinoma. Ann Thorac Surg. 2004;78(1):238-244.

9. Lucena JR. Reseccion de metastasis pulmonares en cancer colorectal [Resection of lung metastases from colorectal cancer]. Cir Esp. 2005;78(6):362-365. Spanish.

10. Iwasaki A, Shirakusa T, Yamashita Y, Noritomi T, Maekawa T, Hamada T. Characteristic differences between patients who have undergone surgical treatment for lung metastasis or hepatic metastasis from colorectal cancer. Thorac Cardiovasc Surg. 2005;53(6):358-364.

11. Van Cutsem E, Nordlinger B, Cervantes A. Advanced colorectal cancer: ESMO clinical practice guidelines for treatment. Ann Oncol. 2010;21(Suppl 5):v93-v97.

12. Cirocchi R, Trastulli S, Boselli C, et al. Radiofrequency ablation in the treatment of liver metastases from colorectal cancer [review]. Cochrane Database Syst Rev. 2012;6:CD006317.

13. McCahill LE, Yothers GA, Sharif S, et al. A phase II trial of 5-fluorouracil, leucovorin, and oxaliplatin (mFOLFOX6) chemotherapy plus bevacizumab (bev) for patients (pts) with unresectable stage IV colon cancer and a synchronous asymptomatic primary tumor: results of NSABP C-10 [abstract]. J Clin Oncol. 2010;28(15 Suppl):3527.

14. Bokemeyer C, Kohne C, Rougier P, Stroh C, Schlichting M, Van Cutsem E. Cetuximab with chemotherapy (CT) as first-line treatment for metastatic colorectal cancer (mCRC): analysis of the CRYSTAL and OPUS studies according to KRAS and BRAF mutation status [abstract]. J Clin Oncol. 2010;28(Suppl 15):3506.

15. Ocvirk J, Brodowicz T, Wrba F, et al. Cetuximab plus FOLFOX6 or FOLFIRI in metastatic colorectal cancer: CECOG trial. World $J$ Gastroenterol. 2010;16(25):3133-3143.

16. Costi R, Di Mauro D, Giordano P, et al. Impact of palliative chemotherapy and surgery on management of stage IV incurable colorectal cancer. Ann Surg Oncol. 2010;17(2):432-440.

17. Poultsides GA, Servais EL, Saltz LB, et al. Outcome of primary tumor in patients with synchronous stage IV colorectal cancer receiving combination chemotherapy without surgery as initial treatment. J Clin Oncol. 2009;27(20):3379-3384.

18. Karoui M, Soprani A, Charachon A, et al. Primary chemotherapy with or without colonic stent for management of unresectable stage IV colorectal cancer. Eur J Surg Oncol. 2010;36(1):58-64.
19. Cirocchi R, Farinella E, Trastulli S, et al. Safety and efficacy of endoscopic colonic stenting as a bridge to surgery in the management of intestinal obstruction due to left colon and rectal cancer: a systematic review and meta-analysis. Surg Oncol. 2013;22(1):14-21.

20. Damjanov N, Weiss J, Haller DG. Resection of the primary colorectal cancer is not necessary in nonobstructed patients with metastatic disease. Oncologist. 2009;14(10):963-969.

21. Dripps RD. New classification of physical status. Anesthesiology. 1963;24:111.

22. Oken MM, Creech RH, Tormey DC, et al. Toxicity and response criteria of the Eastern Cooperative Oncology Group. Am J Clin Oncol. 1982;5(6):649-655.

23. Muratore A, Zorzi D, Bouzari H, et al. Asymptomatic colorectal cancer with un-resectable liver metastases: immediate colorectal resection or up-front systemic chemotherapy? Ann Surg Oncol. 2007;14(2):766-770.

24. Benoist S, Pautrat K, Mitry E, Rougier P, Penna C, Nordlinger B. Treatment strategy for patients with colorectal cancer and synchronous irresectable liver metastases. Br J Surg. 2005;92(9):1155-1160.

25. Galizia G, Lieto E, Orditura M, et al. First-line chemotherapy vs bowel tumor resection plus chemotherapy for patients with unresectable synchronous colorectal hepatic metastases. Arch Surg. 2008;143(4):352-358.

26. Konyalian VR, Rosing DK, Haukoos JS, et al. The role of primary tumour resection in patients with stage IV colorectal cancer. Colorectal Dis. 2007;9(5):430-437.

27. Kleespies A, Fuessl KE, Seelinger H, et al. Determinants of morbidity and survival after elective non-curative resection of stage IV colon and rectal cancer. Int J Colorectal Dis. 2009;24(9):1097-1109.

28. Mik M, Dziki L, Galbfach P, Trzcinski R, Sygut A, Dziki A. Resection of the primary tumour or other palliative procedures in incurable IV stage colorectal cancer patients? Colorectal Dis. 2010; 12(7 Online):e61-e67.

29. Stillwell AP, Ho YH, Veitch C. Systematic review of prognostic factors related to overall survival in patients with stage IV colorectal cancer and unresectable metastases. World J Surg. 2011;35(3):684-692.

30. Katoh H, Yamashita K, Kokuba Y, et al. Surgical resection of stage IV colorectal cancer and prognosis. World J Surg. 2008;32(6):1130-1137.

31. Tebbutt NC, Norman AR, Cunningham D, et al. Intestinal complications after chemotherapy for patients with unresected primary colorectal cancer and synchronous metastases. Gut. 2003;52(4):568-573.

32. Cirocchi R, Trastulli S, Abraha I, et al. Non-resection versus resection for an asymptomatic primary tumour in patients with unresectable stage IV colorectal cancer [review]. Cochrane Database Syst Rev. 2012;8:CD008997.
OncoTargets and Therapy

\section{Publish your work in this journal}

OncoTargets and Therapy is an international, peer-reviewed, open access journal focusing on the pathological basis of all cancers, potential targets for therapy and treatment protocols employed to improve the management of cancer patients. The journal also focuses on the impact of management programs and new therapeutic agents and protocols on

\section{Dovepress}

patient perspectives such as quality of life, adherence and satisfaction The manuscript management system is completely online and includes a very quick and fair peer-review system, which is all easy to use. Visit http://www.dovepress.com/testimonials.php to read real quotes from published authors. 